\title{
Quantity-setting games with a dominant firm
}

\author{
Attila Tasnádi
}

\section{EERI Research Paper Series No 25/2009}

ISSN: 2031-4892

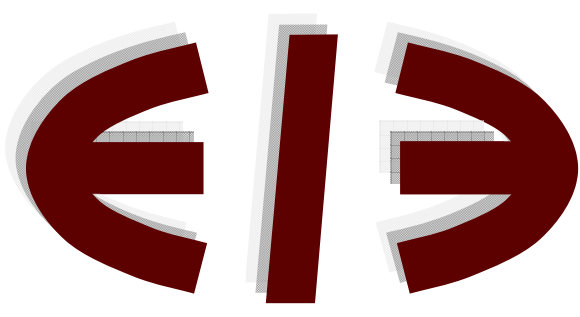

EERI

Economics and Econometrics Research Institute Avenue de Beaulieu 1160 Brussels

Belgium

Tel: +3222993523

Fax: +322 2993523

www.eeri.eu 


\title{
Quantity-setting games with a dominant firm
}

\author{
Attila Tasnádi* \\ Department of Mathematics, Corvinus University of Budapest, \\ H-1093 Budapest, Fővám tér 8, Hungary ${ }^{\dagger}$
}

August 17, 2009.

\begin{abstract}
We consider a possible game-theoretic foundation of Forchheimer's model of dominant-firm price leadership based on quantity-setting games with one large firm and many small firms. If the large firm is the exogenously given first mover, we obtain Forchheimer's model. We also investigate whether the large firm can emerge as a first mover of a timing game.
\end{abstract}

Keywords: Forchheimer; Dominant firm; Price leadership JEL classification: D43; L13

*I am very grateful to Dan Kovenock, Trent Smith and three anonymous referees for many helpful comments and suggestions. The author gratefully acknowledges financial support from the Hungarian Academy of Sciences (MTA) through the Bolyai János research fellowship.

${ }^{\dagger}$ Telephone: (+36 1) 4827442, E-mail: attila.tasnadi@uni-corvinus.hu 


\section{Introduction}

In Forchheimer's model of dominant-firm price leadership (see for example Scherer and Ross, 1990, p. 221) it is assumed that there is one large and many small firms. The large firm is assumed to determine the price in the market and the firms in the competitive fringe act as price takers. Therefore, the large producer sets its price by maximizing profit subject to its residual demand curve. More specifically, the large firm's residual demand curve can be obtained as the horizontal difference of the demand curve and the aggregate supply curve of the competitive fringe. However, this usual description of Forchheimer's model is not derived from the firms' individual profit maximization behavior.

Ono (1982) provided a theoretical analysis of price leadership by investigating a model in which one firm sets the market price, the remaining firms choose their outputs and the price setter serves the residual demand. Hence, one firm uses price as its strategic variable while the remaining firms use quantity as their strategic variable. Under these circumstances Ono demonstrated that there is a firm that accepts the role of the price setter, while the remaining firms prefer to set their quantities. However, Ono leaves open the questions of why the price-setting firm serves the residual demand and why there is just one price-setting firm in the market (since these are assumed in Ono's model).

A complete price-setting game-theoretic foundation of dominant-firm price leadership was given by Deneckere and Kovenock (1992) in the framework of a capacity-constrained Bertrand-Edgeworth duopoly game. Tasnádi (2000) provides another game-theoretic foundation of Forchheimer's model, based on a price-setting game with one large firm and a nonatomic fringe in which all firms have strictly convex cost functions. In a follow-up paper Tasnádi (2004) shows that for the case of strictly convex cost functions, the large firm will not accept the role of the leader in a simple two-period timing game. ${ }^{1}$

In this paper we seek a game-theoretic foundation of the dominant-firm model of price leadership based on quantity-setting games; but in this case the term "price leadership" may not be appropriate since we use quantity as the strategic variable. Nevertheless, we will establish that if the large firm is the exogenously specified first mover and there are sufficiently many "almost negligible" small firms moving second, then equilibrium price and aggregate production of the two-stage quantity-setting game will be very close to the

\footnotetext{
${ }^{1}$ We refer to Rassenti and Wilson (2004) for an experimental investigation of the dominant-firm model of price leadership.
} 
dominant firm price and the Forchheimer market output, respectively. ${ }^{2}$ To show this type of convergence result we will consider a sequence of two-stage quantity-setting games, all having the same efficient firm and an increasing number of less efficient firms, where the total competitive supply of the lessefficient firms remain the same in each market. Hence, an oligopoly market of the sequence is not obtained from another oligopoly market by the entry of new firms.

We find that the quantities of the appropriate sequence of quantitysetting two-stage games will converge to the same values determined by the dominant-firm model of price leadership (Proposition 1). ${ }^{3}$ Thus, a kind of game-theoretic foundation of Forchheimer's dominant-firm model can be given by two-stage quantity-setting games. A similar result has been obtained by Sadanand and Sadanand (1996) in the presence of a sufficiently small but nonvanishing amount of demand uncertainty in a market with one large firm and a continuum of identical small firms. ${ }^{4}$ In this respect, the present paper relaxes the assumptions of identical and infinitely many small firms.

Concerning the endogenous timing of moves, Sadanand and Sadanand (1996) mention in the proof of their Proposition 3 for the deterministic case that the large firm still could be the endogenous quantity leader in the market, but unfortunately this equilibrium outcome of the timing game does not remain unique. This paper adds to Sadanand and Sadanand by showing that nonvanishing demand uncertainty and a continuum of small firms play a crucial role in obtaining the large firm as the endogenous leader (Proposition 2). In particular, most of the small firms do not want to accept the role of the follower.

The remainder of this paper is organized as follows. In Section 2 we describe the framework of our analysis. Section 3 presents a game-theoretic foundation of dominant-firm price leadership based on quantity-setting games, while Section 4 shows that the exogenously given order of moves in Section 3 cannot be endogenized. Finally, Section 5 contains concluding remarks.

\footnotetext{
${ }^{2}$ Purely sequential-move quantity-setting games with identical firms have been investigated from a different viewpoint by Robson (1990) and Anderson and Engers (1992).

${ }^{3}$ Tesoriere (2008) shows for a market with infinitely many quantity-setting firms, in which the firms have identical and linear cost functions, that only first movers produce a positive amount. Of course, his findings cannot support Forchheimer's model since because of the symmetric setting there is no firm with a clear cost advantage.

${ }^{4}$ For a recent contribution on quantity-setting timing games with demand uncertainty see Caron and Lafay (2008).
} 


\section{The framework}

The demand is given by the function $D: \mathbb{R}_{+} \rightarrow \mathbb{R}_{+}$on which we impose the following assumptions in order to ensure the existence of equilibrium in the oligopoly games:

Assumption 1. There exists a positive price $b$ such that $D(p)>0$ if $p<b$, and $D(p)=0$ if $p \geq b$. The demand function $D$ is strictly decreasing on $[0, b]$, twice continuously differentiable on $(0, b)$ and concave on $[0, b]$.

Let $a$ be the horizontal intercept of the demand function, i.e., $D(0)=a$. Clearly, the firms will not produce more than $a$. Let us denote by $P$ the inverse demand function; that is, $P(0)=b, P(q)=D^{-1}(q)$ for all $q \in(0, a)$, and $P(q)=0$ for all $q \geq a$.

The result in Section 3 will be asymptotic in nature and therefore, we will consider a sequence of oligopoly markets $O=\left(O^{n}\right)_{n=1}^{\infty}$. The demand function $D$ is assumed to be the same in every oligopoly market of the sequence $O$. The cost, marginal cost and supply functions in the oligopoly market $O^{n}$ will be denoted by $c_{i}^{n}: \mathbb{R}_{+} \rightarrow \mathbb{R}_{+}, m c_{i}^{n}: \mathbb{R}_{+} \rightarrow \mathbb{R}_{+}$and $s_{i}^{n}: \mathbb{R}_{+} \rightarrow \mathbb{R}_{+}$, respectively $(i \in\{0,1, \ldots, n\})$. Thus, the $n$th oligopoly market of the sequence $O$ is described by $O^{n}=\left\langle\{0,1, \ldots, n\},\left(c_{0}^{n}, c_{1}^{n}, \ldots, c_{n}^{n}\right), D\right\rangle$, where $n$ stands for the number of second movers in case of one exogenously given first mover. We shall denote by $\mathbb{N}$ the set of positive integers.

In order to ensure the existence and at some points also the uniqueness of the equilibrium through our analysis we impose on the firms' cost functions the following assumptions:

Assumption 2. The cost functions $c_{i}^{n}$ are twice continuously differentiable, there are no fixed costs and the cost functions are strictly increasing and strictly convex. Furthermore, $\left(c_{i}^{n}\right)^{\prime}(0)=\lim _{q \rightarrow 0^{+}}\left(c_{i}^{n}\right)^{\prime}(q)=m c_{i}^{n}(0)=0$ and $\lim _{q \rightarrow \infty} m c_{i}^{n}(q)=\infty$ for all $i \in\{0,1, \ldots, n\}$.

Assumption 2 implies that the competitive supply, henceforth briefly supply, at price level $p$ of firm $i$ can be given by $s_{i}^{n}(p):=\left(m c_{i}^{n}\right)^{-1}(p)$ because the supply of firm $i$ at price level $p$ is a solution of the problem $s_{i}^{n}(p)=\arg \max _{q \geq 0} p q-c_{i}^{n}(q)$, which has a unique solution for all $p \geq 0$ because of Assumption 2.

So far we have not made any distinction between the firms. We call firm 0 the large firm and the remaining firms small firms. The usage of this terminology is justified by the following two assumptions.

Assumption 3. The (competitive) supply of firm 0 as well as the aggregate (competitive) supply of firms $1, \ldots, n$ remain the same in every oligopoly 
market of the sequence $O$. Hence, we can denote by $s_{0}=s_{0}^{n}$ the supply of the large firm, by $c_{0}=c_{0}^{n}$ the cost function of the large firm, by $S_{c}=\sum_{i=1}^{n} s_{i}^{n}$ the aggregate supply of the small firms and by $M C_{c}:=S_{c}^{-1}$ its inverse.

Assumption 4. There exists a positive real value $\alpha$ such that

$$
s_{i}^{n}(p)<\frac{\alpha}{n} S_{c}(p)
$$

holds true for any $p \in(0, b]$, for any $n \in \mathbb{N}$ and for any firm $i \in\{1, \ldots, n\}$.

Assumptions 3 and 4 jointly imply that by considering an oligopoly market $O^{n}$ with a sufficiently large index $n$, the supply of any small firm can be regarded as 'almost negligible' compared to the large firm's supply. This justifies the qualifiers large and small.

We want to emphasize that we do not investigate the case of free entry. Clearly, considering a fixed oligopoly market $O^{n}$ and a potential entrant labeled $n+1$ with a given cost function $c_{n+1}^{n}$ satisfying Assumption 2, firm $n+1$ would always enter since it can make positive profits. In particular, two different oligopoly markets $O^{n_{1}}$ and $O^{n_{2}}$ out of the same sequence of oligopoly markets $\left(O^{n}\right)_{n=1}^{\infty}$ are just two different technological scenarios in which large firms have identical supply functions and sets of small firms have identical aggregate supply functions.

It should be mentioned that Anderson and Engers (1994) have developed a model of entry in a multi-period quantity-setting framework with costly capacity investments, for which they determine the number of active firms in the market in function of a uniform fixed cost. More recently, a twostage Stackelberg-type game (similar to the oligopoly markets employed in this paper) with one exogenously given leader allowed to enter in the first period and other followers allowed to enter in the second period has been considered by Etro (2008). ${ }^{5}$ For each firm, entry involves paying fixed entry costs and determining the magnitude of its decision variable. ${ }^{6}$ Since Etro assumes identical firms, his model does not yield Forchheimer's model of dominant firm price leadership.

Now we briefly describe Forchheimer's model of dominant-firm price leadership (for more details we refer to Scherer and Ross, 1990). The dominant firm sets its price by maximizing profit with respect to its residual demand curve, which can be obtained as the horizontal difference of the demand curve and the aggregate supply curve of the competitive fringe. Hence, the residual

\footnotetext{
${ }^{5}$ For more on entry and product differentiation in the two-stage quantity-setting framework see Žigić (2008).

${ }^{6}$ Etro (2008) also investigates the case of price competition.
} 
demand curve is given by $D_{d}(p):=\left(D(p)-S_{c}(p)\right)^{+}$and the dominant firm has to maximize the residual profit function:

$$
\pi_{d}(p):=D_{d}(p) p-c_{0}\left(D_{d}(p)\right),
$$

where we used cost function $c_{0}$ because in our model firm 0 shall play the role of the dominant firm. We can obtain the prices maximizing $\pi_{d}$ by solving

$$
\pi_{d}^{\prime}(p)=D_{d}(p)+D_{d}^{\prime}(p)\left(p-m c_{0}\left(D_{d}(p)\right)\right)=0,
$$

by Assumptions 1 and 2. It can be verified that each stationary point of (1) has to be a strict local maximum, and therefore, the first-order condition (2) gives us the unique solution to the profit maximization problem of a Forchheimer type dominant firm. We call the price maximizing $\pi_{d}$, denoted by $p^{*}$, the dominant-firm price. According to Forchheimer's dominant-firm model of price leadership, the dominant firm chooses price $p^{*}$, the small firms set also price $p^{*}$ and the competitive fringe supplies $S_{c}\left(p^{*}\right)$.

\section{The quantity-setting games}

In this section we consider a sequence of quantity-setting games $O_{q}=$ $\left(O_{q}^{n}\right)_{n=1}^{\infty}$ corresponding to a sequence of oligopoly markets $O=\left(O^{n}\right)_{n=1}^{\infty}$. The firms choose the quantities of production and the market clearing price is determined through an unspecified market-clearing mechanism in each quantity-setting game. Usually, the presence of an auctioneer ${ }^{7}$ is assumed in such types of models (for more details see for instance Tirole, 1988).

The quantity actions of the firms in the $n$th oligopoly market are given by a vector $\mathbf{q}=\left(q_{0}, q_{1}, \ldots, q_{n}\right) \in[0, a]^{n+1}$ that we call from now on a quantity profile. The $n$th quantity-setting game is described by the structure

$$
O_{q}^{n}:=\left\langle\{0,1, \ldots, n\},[0, a]^{n+1},\left(\pi_{i}^{n}\right)_{i=0}^{n}\right\rangle,
$$

where

$$
\pi_{i}^{n}(\mathbf{q}):=P\left(q_{0}+q_{1}+\cdots+q_{n}\right) q_{i}-c_{i}^{n}\left(q_{i}\right)
$$

for any $i \in\{0,1, \ldots, n\}$.

In this section we make the following assumption on the timing of decisions:

\footnotetext{
${ }^{7}$ For a model that does not assume an auctioneer and explains the price formation mechanism see Kreps and Scheinkman (1983). One has to mention that Kreps and Scheinkman's result crucially depends on their imposed assumptions on rationing and cost (see for instance Davidson and Deneckere, 1986; and Deneckere and Kovenock, 1992).
} 
Assumption 5. Let firm 0 be the exogenously specified first mover. The remaining firms move simultaneously following firm 0 .

We will establish a link between our sequence of quantity-setting games and Forchheimer's model of dominant-firm price leadership. In particular the sequence of equilibrium prices of the quantity-setting games converges to the dominant-firm price $p^{*}$ and the aggregate output of the small firms converges to the output of the competitive fringe in Forchheimer's model. This is stated more formally in the following proposition.

Proposition 1. Let $O_{q}=\left(O_{q}^{n}\right)_{n=1}^{\infty}$ be a sequence of quantity-setting oligopoly market games satisfying Assumptions 1-5. Then for any $n \in \mathbb{N}$ the game $O_{q}^{n}$ has a subgame perfect Nash equilibrium and for any sequence of subgame perfect Nash equilibrium profiles $\left(\mathbf{q}^{n}\right)_{n=1}^{\infty}$ we have

$$
\lim _{n \rightarrow \infty} P\left(\sum_{i=0}^{n} q_{i}^{n}\right)=p^{*}, \lim _{n \rightarrow \infty} q_{0}^{n}=D_{d}\left(p^{*}\right) \text { and } \lim _{n \rightarrow \infty} \sum_{i=1}^{n} q_{i}^{n}=S_{c}\left(p^{*}\right) .
$$

Proof. We start with demonstrating that every two-stage game $O_{q}^{n}$ has a subgame perfect Nash equilibrium. Suppose that firm 0 produces an amount of $q_{0} \in[0, a]$ in stage one. Then by our assumptions it follows from Szidarovszky and Yakowitz (1977) that for any $n$ the subgame has a unique Nash equilibrium. For the game $O_{q}^{n}$ we shall denote by $f_{n i}\left(q_{0}\right)(i \in\{1, \ldots, n\})$ the unique equilibrium solution of stage two in response to the large firm's first-stage action $q_{0}$. Furthermore, let $f_{n c}\left(q_{0}\right):=\sum_{i=1}^{n} f_{n i}\left(q_{0}\right)$. The equilibrium of the subgame has to satisfy the first-order conditions

$$
P\left(q_{0}+f_{n c}\left(q_{0}\right)\right)+P^{\prime}\left(q_{0}+f_{n c}\left(q_{0}\right)\right) f_{n i}\left(q_{0}\right)-m c_{i}^{n}\left(f_{n i}\left(q_{0}\right)\right)=0,
$$

$(i \in\{1, \ldots, n)\}$. The Implicit Function Theorem implies that the functions $f_{n i}$ and $f_{n c}$ are continuous and differentiable. Thus, the large firm's first-stage profit function

$$
\widehat{\pi}_{0}\left(q_{0}\right):=\pi_{0}\left(q_{0}, f_{n 1}\left(q_{0}\right), \ldots, f_{n n}\left(q_{0}\right)\right)=P\left(q_{0}+f_{n c}\left(q_{0}\right)\right) q_{0}-c_{0}\left(q_{0}\right)
$$

is continuous, and therefore, it follows that the game $O_{q}^{n}$ has a subgame perfect Nash equilibrium.

We take a sequence of subgame perfect Nash equilibrium quantity profiles $\mathbf{q}^{n}$. Let the small firms aggregate production be $q_{c}^{n}:=\sum_{i=1}^{n} q_{i}^{n}$. The sequence $\left(q_{0}^{n}, q_{c}^{n}\right)_{n=1}^{\infty}$ has at least one cluster point since it is bounded. We pick an arbitrary convergent subsequence form the sequence $\left(q_{0}^{n}, q_{c}^{n}\right)_{n=1}^{\infty}$. For notational convenience we suppose that $\left(q_{0}^{n}, q_{c}^{n}\right)_{n=1}^{\infty}$ is already convergent. We shall denote by $\left(\bar{q}_{0}, \bar{q}_{c}\right)$ its limit point. Note that $q_{i}^{n}=f_{n i}\left(q_{0}^{n}\right)$ and $q_{c}^{n}=f_{n c}\left(q_{0}^{n}\right)$. 
The small firms' equilibrium actions $\left(q_{i}^{n}\right)_{i=1}^{n}$ in stage two have to satisfy the following first-order conditions

$$
\frac{\partial \pi_{i}}{\partial q_{i}}\left(\mathbf{q}^{n}\right)=P\left(q_{0}^{n}+q_{c}^{n}\right)+P^{\prime}\left(q_{0}^{n}+q_{c}^{n}\right) q_{i}^{n}-m c_{i}^{n}\left(q_{i}^{n}\right)=0 .
$$

We claim that $\lim _{n \rightarrow \infty} q_{i}^{n}=0$, where in case of a double sequence $a_{i}^{n}$ with $i, n \in \mathbb{N}$ and $i \leq n$ we write $\lim _{n \rightarrow \infty} a_{i}^{n}=a$ if

$$
\forall \varepsilon>0: \exists n_{0} \in \mathbb{N}: \forall n \geq n_{0}: \forall i \in\{1,2, \ldots, n\}:\left|a_{i}^{n}-a\right|<\varepsilon .
$$

From (5) and Assumption 4 we obtain that

$$
\begin{aligned}
q_{i}^{n} & =s_{i}^{n}\left(P\left(q_{0}^{n}+q_{c}^{n}\right)+P^{\prime}\left(q_{0}^{n}+q_{c}^{n}\right) q_{i}^{n}\right) \\
& <\frac{\alpha}{n} S_{c}\left(P\left(q_{0}^{n}+q_{c}^{n}\right)+P^{\prime}\left(q_{0}^{n}+q_{c}^{n}\right) q_{i}^{n}\right) \leq \frac{\alpha}{n} S_{c}(b)
\end{aligned}
$$

for any $i \in\{1, \ldots, n\}$. Thus, we have $\lim _{n \rightarrow \infty} q_{i}^{n}=0$.

Let $p^{n}:=P\left(q_{0}^{n}+q_{c}^{n}\right), r^{n}:=P^{\prime}\left(q_{0}^{n}+q_{c}^{n}\right)$, and $u^{n}:=P^{\prime \prime}\left(q_{0}^{n}+q_{c}^{n}\right)$. Note that $p^{n} \geq 0, r^{n}<0$ and $u^{n} \leq 0$ for all $n \in \mathbb{N}$. We shall denote by $\bar{p}, \bar{r}$, and $\bar{u}$ the corresponding limit points of sequences $\left(p^{n}\right)_{n=1}^{\infty},\left(r^{n}\right)_{n=1}^{\infty}$, and $\left(u^{n}\right)_{n=1}^{\infty}$. By taking limits in (5) we obtain

$$
\bar{p}=\lim _{n \rightarrow \infty} m c_{i}^{n}\left(q_{i}^{n}\right)
$$

The following three auxiliary statements can be derived ${ }^{8}$ :

$$
\begin{gathered}
\bar{p}=M C_{c}\left(\bar{q}_{c}\right) \\
f_{n c}^{\prime}=-1+\frac{1}{1+\sum_{i=1}^{n} \frac{P^{\prime}+P^{\prime \prime} f_{n i}}{P^{\prime}-\left(m c_{i}^{n}\right)^{\prime}}} .
\end{gathered}
$$

and

$$
\lim _{n \rightarrow \infty} \sum_{i=1}^{n} \frac{r^{n}+u^{n} q_{i}^{n}}{r^{n}-\left(m c_{i}^{n}\right)^{\prime}\left(q_{i}^{n}\right)}=-\frac{\bar{r}}{M C_{c}^{\prime}\left(\bar{q}_{c}\right)} .
$$

Now, substituting (10) into (9) yields

$$
\lim _{n \rightarrow \infty} f_{n c}^{\prime}\left(q_{0}^{n}\right)=-\frac{\bar{r}}{\bar{r}-M C_{c}^{\prime}\left(\bar{q}_{c}\right)},
$$

which we need for determining the large firm's behavior.

\footnotetext{
${ }^{8}$ The calculations of $(8),(9)$ and $(10)$ are quite tedious and therefore, relegated to the Appendix.
} 
The sequence of the large firm's decisions $\left(q_{0}^{n}\right)_{n=1}^{\infty}$ has to satisfy the following first-order condition derived from (4):

$$
\widehat{\pi}_{0}^{\prime}\left(q_{0}^{n}\right)=P\left(q_{0}^{n}+q_{c}^{n}\right)+P^{\prime}\left(q_{0}^{n}+q_{c}^{n}\right)\left(1+f_{n c}^{\prime}\left(q_{0}^{n}\right)\right) q_{0}^{n}-m c_{0}\left(q_{0}^{n}\right)=0 .
$$

If we take limits in equation (12), then in consideration of (11)

$$
\bar{p}=m c_{0}\left(\bar{q}_{0}\right)-\bar{r}\left(1-\frac{\bar{r}}{\bar{r}-M C_{c}^{\prime}\left(\bar{q}_{c}\right)}\right) \bar{q}_{0}
$$

must hold. From (8) and (13) we can easily obtain that $\bar{p}$ is a solution to (2):

$$
\pi_{d}^{\prime}(\bar{p})=\bar{q}_{0}+\left(\frac{1}{\bar{r}}-\frac{1}{M C_{c}^{\prime}\left(\bar{q}_{c}\right)}\right)\left(\frac{\bar{r} M C_{c}^{\prime}\left(\bar{q}_{c}\right)}{\bar{r}-M C_{c}^{\prime}\left(\bar{q}_{c}\right)}\right) \bar{q}_{0}=0 .
$$

Thus, $\bar{p}$ is indeed a solution of equation (2). Since equation (2) has a unique solution we also conclude that the sequence $\left(p^{n}\right)_{n=1}^{\infty}$ has only one cluster point. Therefore, $p^{*}=\bar{p}$. Furthermore, it follows that all convergent subsequences of the bounded sequence $\left(q_{0}^{n}, q_{c}^{n}\right)_{n=1}^{\infty}$ have the same limit point, which means that $\left(q_{0}^{n}, q_{c}^{n}\right)_{n=1}^{\infty}$ is convergent. Hence, (8) implies $\lim _{n \rightarrow \infty} \sum_{i=1}^{n} q_{i}^{n}=S_{c}\left(p^{*}\right)$, and therefore, $\lim _{n \rightarrow \infty} q_{0}^{n}=D_{d}\left(p^{*}\right)$ by $p^{*}=P\left(\bar{q}_{0}+\bar{q}_{c}\right)$.

We illustrate Proposition 1 by considering the case of linear demand, quadratic cost functions and the small firms having identical cost functions, because in this case (2), (5) and (12) can be solved explicitly.

Example 1. $D(p)=1-p, c_{0}(q)=\frac{a}{2} q^{2}$ and $c_{i}(q)=n \frac{b}{2} q^{2}$ for all $i=1, \ldots, n$.

Maximizing profits with respect to $D_{d}^{-1}(q)=\frac{b(1-q)}{1+b}$ gives us the output

$$
q_{0}^{F}=\frac{b}{a(b+1)+2 b}
$$

of the Forchheimer-type dominant firm. Turning to the two-stage quantitysetting game with the large firm as the exogenously given first mover, if the large firm produces $q_{0}$ in stage 1 , then the small firms will produce

$$
q_{i}=\frac{1-q_{1}}{1+n(b+1)} \quad \text { for all } i=1, \ldots, n
$$

in stage 2. Taking the reactions of the small firms into consideration, the large firm produces

$$
q_{1}=\frac{\frac{1+n b}{1+n(b+1)}}{a+2 \frac{1+n b}{1+n(b+1)}} \rightarrow \frac{\frac{b}{b+1}}{a+\frac{2 b}{b+1}}=\frac{b}{a(b+1)+2 b}=q_{1}^{F}
$$

as $n$ tends to infinity. It is straightforward to check that the aggregate output of the small firms in stage 2 converges to the output of the competitive fringe in Forchheimer's model. 


\section{Endogenous timing}

Proposition 1 ensures that a two-stage quantity-setting game with a large firm as the exogenously given first mover and many almost negligible small firms as exogenously given followers almost results in Forchheimer's dominant firm model of price leadership. A crucial question to be addressed is why the large firm should accept the role of the leader and the small firms the role of the follower. By remaining in a deterministic framework and considering only quantity as a possible strategic variable, we give a negative answer to this question by applying Matsumura's (1999) general result on timing in quantity-setting games, which allows us to investigate a quite complex timing game.

We have to emphasize that the outcome of the quantity-setting timing game is independent of the supply structure of the firms and thus, we will not have to consider a sequence of quantity-setting games as in Section 3. Let us briefly sketch Matsumura's (1999) timing game and result. Suppose that there are $n+1$ firms and $m+1$ stages. In the first stage (period 0 ) each firm selects its production period $t \in\{1,2, \ldots, m\}$. A firm $i$ producing $q_{i}$ in period $t_{i} \in\{2, \ldots, m\}$ observes any production decision $q_{j}$ made in period $t_{j} \in\left\{1, \ldots, t_{i}-1\right\}$ and firm $i$ does not know the set of firms producing in the same period $t_{i}$, which means that this timing game can be regarded as an extension of the 'extended game with action commitment' investigated by Hamilton and Slutsky (1990). ${ }^{9}$ At the end of period $m$ the market opens and each firm sells its entire production at the market clearing price. That is, firm $i$ achieves $\pi_{i}\left(q_{0}, q_{1}, \ldots, q_{n}\right)=P\left(\sum_{j=0}^{n} q_{j}\right) q_{i}-c_{i}\left(q_{i}\right)$ profits.

In order to determine the outcome of the introduced timing game Matsumura (1999) imposes three assumptions on two-stage games with exogenous timing. The set of leaders, denoted by $S^{L}$, consisting of those firms producing in period 1, and the set of followers, denoted by $S^{F}$, consisting of those firms producing in period 2, are exogenously given. Firms moving in the same period move simultaneously and the followers observe the production quantities of the leaders. The production $q_{i}$ of a firm $i \in\{0,1, \ldots, n\} \backslash\left(S^{L} \cup S^{F}\right)$ is exogenously given and common knowledge. Matsumura assumes that all two-stage games with exogenous sequencing have a unique equilibrium in pure strategies (Matsumura, 1999, Assumption 1), every firm strictly prefers moving simultaneously with the other firms to being the only follower (Matsumura, 1999, Assumption 2), and every firm strictly prefers moving before the other firms to moving simultaneously with them (Matsumura, 1999, As-

\footnotetext{
${ }^{9}$ At the end of this section we will also consider the 'extended game with observable action delay' in which the firms know the set of firms moving in the same time period.
} 
sumption 3). Under these three assumptions Matsumura (1999, Proposition 3 ) shows that in any equilibrium of the $m+1$ period timing game at most one firm does not move in the first period.

We will establish that our assumptions imposed on the cost functions and the demand curve in Section 2 imply Matsumura's second and third assumptions. ${ }^{10}$ Thus, we have to assume explicitly only the following assumption.

Assumption 6. Any two-stage game with exogenous sequencing possesses a unique equilibrium in pure strategies.

Assumption 6 is needed because there is no simple condition in our framework, which guarantees the existence and uniqueness of the equilibrium for two-stage games. Sherali (1984) provides sufficient conditions for the existence and uniqueness of the subgame perfect equilibrium. However, Sherali's (1984) conditions for uniqueness cannot be applied in our model since we have to allow asymmetric cost functions, while Sherali (1984, Theorem 5) requires that the firms' moving in the first period have identical cost functions. ${ }^{11}$ Moreover, Ehrenmann (2004) points to the difficulty of the problem even in case of identical leaders by presenting an example of a triopoly market with two leaders having identical linear cost functions, a follower having also a linear cost function and a linear demand function that possesses also non-symmetric equilibria concerning just the first-stage output of the leaders. These results indicate also that checking Matsumura's (1999) Assumptions 2 and 3 for the oligopolistic case is a far more difficult task than for the simple duopolistic case for which the results are well-known. While the case of just one leader has been investigated in the literature, for example, by Sherali, Soyster and Murphy (1983), the case of just one follower has not got, as far as we know, real attention in the literature - with the exception of the above-mentioned counterexample by Ehrenmann (2004).

The next proposition determines the endogenous order of moves in quantity-setting games.

Proposition 2. Let $O_{q}$ be a quantity-setting oligopoly game satisfying Assumptions 1, 2, and 6 . Then in an equilibrium of the $m+1$ period Matsumura timing game at most one firm does not set its output in the first period.

\footnotetext{
${ }^{10}$ Matsumura (1996) gives a sufficient condition which ensures that these two Assumtions are satisfied. However, we cannot apply this latter result in our framework without imposing further assumptions.

${ }^{11}$ For more on the existence and the uniqueness of the subgame perfect Nash equilibrium of two-stage quantity-setting games we refer to Tobin (1992), Flåm, Mallozzi and Morgan (2002), and Mallozzi and Morgan (2005). DeMiguel and Xu (2009) shows existence in case of stochastic demand. For the easier case of linear demand and identical firms with linear cost functions Daughety (1990) investigates welfare effects, mergers and concentration in the market.
} 
Proof. In order to demonstrate the proposition we have only to verify that our Assumptions 1, 2 and 6 imply Matsumura's (1999) Assumptions 2 and 3. Hence, we have to consider three different two-stage games with exogenous timing. In particular, the Cournot game in which each firm moves in the same time period, the game with only one leader and the game with only one follower.

Since the Assumptions 1 and 2 ensure the existence of a unique Nash equilibrium in pure strategies ${ }^{12}$ (see for instance Szidarovszky and Yakowitz, 1977) the first-order conditions below determine the outcome of the Cournot game.

$$
\frac{\partial}{\partial q_{i}} \pi_{i}\left(q_{0}, q_{1}, \ldots, q_{n}\right)=P\left(\sum_{j=0}^{n} q_{j}\right)+P^{\prime}\left(\sum_{j=0}^{n} q_{j}\right) q_{i}-m c_{i}\left(q_{i}\right)=0
$$

Regarding that our assumptions imply that (14) has an interior solution, by rearranging (14) we can obtain the next useful equation:

$$
P^{\prime}\left(\sum_{j=0}^{n} q_{j}\right)=\frac{m c_{i}\left(q_{i}\right)-P\left(\sum_{j=0}^{n} q_{j}\right)}{q_{i}}<0 .
$$

We shall denote the Cournot solution by $\left(q_{i}^{c}\right)_{i=0}^{n}$.

Next we investigate the game with only one leader. Suppose that firm $i$ is the leader. Clearly, the leader achieves the same profit as in the Cournot game by setting its production to $q_{i}^{c} \cdot{ }^{13}$ Hence, it remains to show that the leader earns more as a leader than by moving simultaneously with the other firms. Given the production $q_{i}$ of firm $i$ the followers play in the subgame a simultaneous-move quantity-setting game subject to the inverse demand curve $\widetilde{P}(q)=P\left(q+q_{i}\right)$. Thus, the subgame has a unique Nash equilibrium because of Assumptions 1 and 2. Let us denote by $Q_{-i}\left(q_{i}\right)$ the aggregate production of the followers in response of the leader's output $q_{i}$. Then firm $i$ maximizes the function $\widetilde{\pi}_{i}\left(q_{i}\right):=P\left(q_{i}+Q_{-i}\left(q_{i}\right)\right) q_{i}-c_{i}\left(q_{i}\right)$. It can be easily checked ${ }^{14}$ that $Q_{-i}^{\prime}\left(q_{i}\right) \in(-1,0)$ holds for all $q_{i} \in(0, a)$. Therefore, in consideration of (14) and $q_{i}^{c}+Q_{-i}\left(q_{i}^{c}\right)=\sum_{j=0}^{n} q_{j}^{c}$ it follows that

$$
\tilde{\pi}_{i}^{\prime}\left(q_{i}^{c}\right)=P\left(q_{i}^{c}+Q_{-i}\left(q_{i}^{c}\right)\right)+\left(1+Q_{-i}^{\prime}\left(q_{i}^{c}\right)\right) P^{\prime}\left(q_{i}^{c}+Q_{-i}\left(q_{i}^{c}\right)\right) q_{i}^{c}-m c_{i}\left(q_{i}^{c}\right)>0
$$

\footnotetext{
${ }^{12}$ Note that this is also guaranteed by Assumption 6, but we wanted to emphasize that Assumption 6 is not needed at this stage of the proof.

${ }^{13}$ This has been already shown by Sherali, Soyster and Murphy (1983, Lemma 6).

${ }^{14}$ Note that by deriving (9) we have carried out the necessary calculations since (9) does not depend on the special role played by firm 0 in Proposition 1.
} 
which in turn implies that firm $i$ makes more profits by producing more than $q_{i}^{c}$. This means that Matsumura's (1999) Assumption 3 is fulfilled.

Finally, we have to investigate the two-stage game with only one follower. Suppose that firm $i$ is the follower. Again we denote by $Q_{-i}$ the aggregate production of the other firms but now $q_{i}$ depends on $Q_{-i}$. For a given amount $Q_{-i}$ firm $i$ has to maximize the function $\widehat{\pi}_{i}\left(q_{i}\right):=P\left(q_{i}+Q_{-i}\right) q_{i}-c_{i}\left(q_{i}\right)$, which has a unique solution determined by

$$
\widehat{\pi}_{i}^{\prime}\left(q_{i}\right)=P\left(q_{i}+Q_{-i}\right)+P^{\prime}\left(q_{i}+Q_{-i}\right) q_{i}-m c_{i}\left(q_{i}\right)=0 .
$$

From this first-order condition we obtain that

$$
\frac{\mathrm{d} q_{i}}{\mathrm{~d} Q_{-i}}=-\frac{P^{\prime}\left(q_{i}+Q_{-i}\right)+P^{\prime \prime}\left(q_{i}+Q_{-i}\right) q_{i}}{2 P^{\prime}\left(q_{i}+Q_{-i}\right)+P^{\prime \prime}\left(q_{i}+Q_{-i}\right) q_{i}-m c_{i}^{\prime}\left(q_{i}\right)},
$$

which implies that $\mathrm{d} q_{i} / \mathrm{d} Q_{-i} \in(-1,0)$ and $\mathrm{d}\left(q_{i}+Q_{-i}\right) / \mathrm{d} Q_{-i} \in(0,1)$ for any $Q_{-i} \in[0, a)$. This means that an increase in the first-stage aggregate output decreases the followers output and increases the total output. Let us remark that $\mathrm{d} q_{i} / \mathrm{d} q_{j}=\mathrm{d} q_{i} / \mathrm{d} Q_{-i}$ holds true for any firm $j \neq i$. The first-stage quantities of firms $\{0,1, \ldots, n\} \backslash\{i\}$ are determined (because of Assumption $6)$ by the first-order conditions

$$
P\left(q_{i}\left(Q_{-i}\right)+Q_{-i}\right)+\left(1+\frac{\mathrm{d} q_{i}}{\mathrm{~d} q_{j}}\right) P^{\prime}\left(q_{i}\left(Q_{-i}\right)+Q_{-i}\right) q_{j}-m c_{j}\left(q_{j}\right)=0 .
$$

Clearly, for an equilibrium profile we must have $q_{i}+Q_{-i} \in[0, a)$ and $q_{j}>0$ for all $j \neq i$. Hence, by rearranging (18) we obtain

$$
\left(1+\frac{\mathrm{d} q_{i}}{\mathrm{~d} Q_{-i}}\right) P^{\prime}\left(q_{i}\left(Q_{-i}\right)+Q_{-i}\right)=\frac{m c_{j}\left(q_{j}\right)-P\left(q_{i}\left(Q_{-i}\right)+Q_{-i}\right)}{q_{j}}<0
$$

for all $j \neq i$. We shall denote the solution to equations (16) and (18) by $\left(q_{i}^{*}\right)_{i=0}^{n}$.

We claim that $q_{i}^{c}+Q_{-i}^{c}<q_{i}^{*}+Q_{-i}^{*}$. Suppose that this is not the case; i.e., $q_{i}^{c}+Q_{-i}^{c} \geq q_{i}^{*}+Q_{-i}^{*}$ holds true. Then we must have $Q_{-i}^{c} \geq Q_{-i}^{*}$ and therefore, we can find a firm $j \neq i$ for which we have $q_{j}^{c} \geq q_{j}^{*}$. For this firm $j$ we can 
derive the following inequalities:

$$
\begin{aligned}
\left(1+\frac{\mathrm{d} q_{i}}{\mathrm{~d} Q_{-i}}\right) P^{\prime}\left(q_{i}^{*}+Q_{-i}^{*}\right) & >P^{\prime}\left(q_{i}^{*}+Q_{-i}^{*}\right) \geq P^{\prime}\left(q_{i}^{c}+Q_{-i}^{c}\right) \\
& =\frac{m c_{j}\left(q_{j}^{c}\right)-P\left(q_{j}^{c}+Q_{-j}^{c}\right)}{q_{j}^{c}} \\
& \geq \frac{m c_{j}\left(q_{j}^{c}\right)-P\left(q_{j}^{*}+Q_{-j}^{*}\right)}{q_{j}^{c}} \\
& \geq \frac{m c_{j}\left(q_{j}^{*}\right)-P\left(q_{j}^{*}+Q_{-j}^{*}\right)}{q_{j}^{*}},
\end{aligned}
$$

by applying $\mathrm{d} q_{i} / \mathrm{d} Q_{-i}=\mathrm{d} q_{i} / \mathrm{d} q_{j} \in(-1,0)$, Assumption 1, (15), Assumption 1 and by observing that the function $f(q):=\left(m c_{j}(q)-P\left(q_{j}^{*}+Q_{-j}^{*}\right)\right) / q$ is strictly increasing on $\left[q_{j}^{*}, q_{j}^{c}\right]$. But this contradicts (19).

Since $q_{i}^{c}+Q_{-i}^{c}<q_{i}^{*}+Q_{-i}^{*}$ and (17) imply $q_{i}^{c}>q_{i}^{*}$ and $P\left(q_{i}^{c}+Q_{-i}^{c}\right)>$ $P\left(q_{i}^{*}+Q_{-i}^{*}\right)$ we can deduce that firm $i$ realizes more profits in the Cournot game than in the game in which it plays the role of the only one follower. Thus, Matsumura's (1999) Assumption 2 is also satisfied.

Proposition 2 implies for quantity-setting games satisfying the assumptions in Proposition 2 that none of the firms will become the unique leader in the market if there are at least three firms and therefore, Forchheimer's model will not emerge.

If we consider the extended timing game with observable action delay, ${ }^{15}$ then we will not have an equilibrium with one follower, while every firm moving in the first period will be an equilibrium. This follows immediately from Matsumura's (1999) Assumption 2.

\section{Concluding remarks}

The intuition behind Proposition 1 is quite straightforward: If we consider the Cournot game which occurs after firm 0 has chosen its quantity $q_{0}$, then the outcome of the subgame played by the remaining firms will converge to the competitive one in the residual market as $n$ becomes large under appropriate assumptions. Thus, in the limit the price in the market must equal the marginal costs of the small firms and therefore, if we were allowed

\footnotetext{
${ }^{15}$ In case of observable action delay, a firm does not only know about the quantities of those firms moving earlier, but also the group of those firms with which it will move in the subsequent period.
} 
to exchange the order of the limits, then Proposition 1 would follow. In particular, the order of maximizing the profits of the large firm and taking infinitely many small firms has to be exchanged.

Of course, it is not at all clear that we can exchange the order of the limits in the intuitive proof described above. Nevertheless, if we would like to apply existing convergence results for Cournot games (see, for instance, Ruffin, 1971 and Novshek, 1985), then these convergence results would need to be extended substantially. In particular, to exchange the order of the limits we would need to prove that the convergence is uniform in the large firm's action $q_{0}$. Hence, working out the described intuitive proof does not necessarily result in a shorter proof of Proposition 1.

Finally, we would like to mention that Example 1 could be suitable to illustrate (in textbooks on Industrial Organization) how Forchheimer's model can be implemented.

\section{Appendix}

Proof of (8). In order to verify (8) note that by (7) we have

$$
\forall \varepsilon>0: \exists n_{0} \in \mathbb{N}: \forall n \geq n_{0}: \forall i \in\{1, \ldots, n\}:\left|m c_{i}^{n}\left(q_{i}^{n}\right)-\bar{p}\right|<\varepsilon .
$$

Select values $\widehat{q}_{i}^{n}$ and $\widetilde{q}_{i}^{n}$ such that $m c_{i}^{n}\left(\widehat{q}_{i}^{n}\right)=\bar{p}-\varepsilon$ and $m c_{i}^{n}\left(\widetilde{q}_{i}^{n}\right)=\bar{p}+\varepsilon$. From $\widehat{q}_{i}^{n} \leq q_{i}^{n} \leq \widetilde{q}_{i}^{n}$ it follows that $\widehat{q}_{c}^{n} \leq q_{c}^{n} \leq \widetilde{q}_{c}^{n}$, which in turn implies $M C_{c}\left(\widehat{q}_{c}^{n}\right) \leq$ $M C_{c}\left(q_{c}^{n}\right) \leq M C_{c}\left(\widetilde{q}_{c}^{n}\right)$. Since $M C_{c}\left(\widehat{q}_{c}^{n}\right)=\bar{p}-\varepsilon$ and $M C_{c}\left(\widetilde{q}_{c}^{n}\right)=\bar{p}+\varepsilon$ we obtain, by the continuity of $M C_{c}$, equation (8).

Proof of (9). Differentiating (3) with respect to $q_{0}$ we obtain

$$
\left(1+f_{n c}^{\prime}\right) P^{\prime}+f_{n i}^{\prime} P^{\prime}+\left(1+f_{n c}^{\prime}\right) P^{\prime \prime} f_{n i}-f_{n i}^{\prime}\left(m c_{i}^{n}\right)^{\prime}=0,
$$

where we have omitted the arguments of the functions in order to shorten the expression. Rearranging (21) yields

$$
f_{n i}^{\prime}=-\frac{P^{\prime}+P^{\prime \prime} f_{n i}}{P^{\prime}-\left(m c_{i}^{n}\right)^{\prime}}\left(1+f_{n c}^{\prime}\right)
$$

Summing (21) for all $i \in\{1, \ldots, n\}$ we get

$$
n P^{\prime}+P^{\prime \prime} f_{n c}+\left((n+1) P^{\prime}+P^{\prime \prime} f_{n c}\right) f_{n c}^{\prime}-\sum_{i=1}^{n} f_{n i}^{\prime}\left(m c_{i}^{n}\right)^{\prime}=0 .
$$


Substituting (22) for $f_{n i}^{\prime}$ in (23) we can express $f_{n c}^{\prime}$ and after the necessary rearrangements we obtain $(9)$.

Proof of (10). First, we prove

$$
\lim _{n \rightarrow \infty} \sum_{i=1}^{n} \frac{1}{\left(m c_{i}^{n}\right)^{\prime}\left(q_{i}^{n}\right)}=\frac{1}{M C_{c}^{\prime}\left(\bar{q}_{c}\right)} .
$$

Let $p_{i}^{n}:=m c_{i}^{n}\left(q_{i}^{n}\right), \widehat{p}^{n}:=\min _{i=1, \ldots, n} p_{i}^{n}$ and $\widetilde{p}^{n}:=\max _{i=1, \ldots, n} p_{i}^{n}$. Then, by (20) and the continuity of $S_{c}^{\prime}$ we can find to all $\varepsilon>0$ an $n_{0} \in \mathbb{N}$ such that for all $n \geq n_{0}$ we have

$$
S_{c}^{\prime}(\bar{p})-\varepsilon \leq S_{c}^{\prime}\left(\widehat{p}^{n}\right) \leq \sum_{i=1}^{n}\left(s_{i}^{n}\right)^{\prime}\left(p_{i}^{n}\right) \leq S_{c}^{\prime}\left(\widehat{p}^{n}\right) \leq S_{c}^{\prime}(\bar{p})+\varepsilon .
$$

Thus,

$$
\lim _{n \rightarrow \infty} \sum_{i=1}^{n} \frac{1}{\left(m c_{i}^{n}\right)^{\prime}\left(q_{i}^{n}\right)}=\lim _{n \rightarrow \infty} \sum_{i=1}^{n}\left(s_{i}^{n}\right)^{\prime}\left(p_{i}^{n}\right)=S_{c}^{\prime}(\bar{p})=\frac{1}{M C_{c}^{\prime}\left(\bar{q}_{c}\right)},
$$

where the second equality follows from (25) while the last from (8).

Finally, we check (10). Consider

$$
\sum_{i=1}^{n} \frac{r^{n}+u^{n} q_{i}^{n}}{r^{n}-\left(m c_{i}^{n}\right)^{\prime}\left(q_{i}^{n}\right)}=\sum_{i=1}^{n} \frac{r^{n}}{r^{n}-\left(m c_{i}^{n}\right)^{\prime}\left(q_{i}^{n}\right)}+\sum_{i=1}^{n} \frac{u^{n} q_{i}^{n}}{r^{n}-\left(m c_{i}^{n}\right)^{\prime}\left(q_{i}^{n}\right)},
$$

where the second summand tends to 0 since for all $K>0$ we can find an $m_{1} \in \mathbb{N}$ such that for all $n \geq m_{1}$ we have $\left(m c_{i}^{n}\right)^{\prime}\left(q_{i}^{n}\right)-r^{n}>K$ for all $i \in\{1, \ldots, n\}$ because $\lim _{n \rightarrow \infty}\left(m c_{i}^{n}\right)^{\prime}\left(q_{i}^{n}\right)=\infty$; and therefore,

$$
\lim _{n \rightarrow \infty} \sum_{i=1}^{n} \frac{u^{n} q_{i}^{n}}{r^{n}-\left(m c_{i}^{n}\right)^{\prime}\left(q_{i}^{n}\right)} \leq \lim _{n \rightarrow \infty} \sum_{i=1}^{n} \frac{u^{n} q_{i}^{n}}{-K}=\frac{\bar{u} \bar{q}_{c}}{-K}
$$

for all $K>0$. We show that the first summand in (26) tends to $-\bar{r} / M C_{c}^{\prime}\left(\bar{q}_{c}\right)$ by two inequalities. First,

$$
\lim _{n \rightarrow \infty} \sum_{i=1}^{n} \frac{r^{n}}{r^{n}-\left(m c_{i}^{n}\right)^{\prime}\left(q_{i}^{n}\right)} \leq-\lim _{n \rightarrow \infty} \sum_{i=1}^{n} \frac{r^{n}}{\left(m c_{i}^{n}\right)^{\prime}\left(q_{i}^{n}\right)}=-\frac{\bar{r}}{M C_{c}^{\prime}\left(\bar{q}_{c}\right)}
$$

by (24). Second, to any $\varepsilon>0$ there exists a positive integer $m_{2}$ such that for all $n \geq m_{2}$ we have

$$
0 \leq\left(m c_{i}^{n}\right)^{\prime}\left(q_{i}^{n}\right)-r^{n}<(1+\varepsilon)\left(m c_{i}^{n}\right)^{\prime}\left(q_{i}^{n}\right)
$$


for all $i \in\{1, \ldots, n\}$, which in turn implies that

$$
\frac{r^{n}}{r^{n}-\left(m c_{i}^{n}\right)^{\prime}\left(q_{i}^{n}\right)}>-\frac{r^{n}}{(1+\varepsilon)\left(m c_{i}^{n}\right)^{\prime}\left(q_{i}^{n}\right)} .
$$

Thus, by (24)

$$
\lim _{n \rightarrow \infty} \sum_{i=1}^{n} \frac{r^{n}}{r^{n}-\left(m c_{i}^{n}\right)^{\prime}\left(q_{i}^{n}\right)} \geq-\frac{\bar{r}}{M C_{c}^{\prime}\left(\bar{q}_{c}\right)},
$$

and we have established (10).

\section{References}

[1] Anderson, S.P., and Engers, M. (1992): "Stackelberg versus Cournot oligopoly equilibrium." International Journal of Industrial Organization 10: $127-135$.

[2] Anderson, S.P., and Engers, M. (1994): "Strategic investment and timing of entry." International Economic Review 35: 833-853.

[3] Caron, C., and Lafay, T. (2008): "How risk disciplines pre-commitment." Theory and Decision 65: 205-226.

[4] Daughety, A.F. (1990): "Beneficial concentration." American Economic Review 80: 1231-1237.

[5] Davidson, C., and Deneckere, R. (1986): "Long-run competition in capacity, short-run competition in price, and the Cournot model." Rand Journal of Economics 17: 404-415.

[6] Deneckere, R., and Kovenock, D. (1992): "Price leadership." Review of Economic Studies 59: 143-162.

[7] DeMiguel, V., and Xu, H. (2009): "A stochastic multiple leader Stackelberg model: Analysis, computation, and application." Operations Research, forthcoming, DOI: 10.1287/opre.1080.0686

[8] Ehrenmann, A. (2004): "Manifolds of multi-leader Cournot equilibria." Operations Research Letters 32 32: 121-125.

[9] Etro, F. (2008): "Stackelberg competition with endogenous entry." Economic Journal 118: 1670-1697. 
[10] Flåm, S.D., Mallozzi, L. and Morgan, J. (2002): "A new look for Stackelberg-Cournot equilibria in oligopolistic markets." Economic Theory 20: 183-188.

[11] Hamilton, J.H., and Slutsky, S.M. (1990): "Endogenous timing in duopoly games: Stackelberg or Cournot equilibria." Games and Economic Behavior 2: 29-46.

[12] Kreps, D.M., and Scheinkman, J.A. (1983): "Quantity precommitment and Bertrand competition yield Cournot outcomes." Bell Journal of Economics 14: 326-337.

[13] Mallozzi, L. and Morgan, J. (2005): "Oligopolistic markets with leadership and demand functions possibly discontinuous." Journal of Optimization Theory and Applications 125: 393-407.

[14] Matsumura, T. (1996): "Essays in oligopoly with endogenous sequencing." Chapter 4 in Doctoral Dissertation, University of Tokyo.

[15] Matsumura, T. (1999): "Quantity-setting oligopoly with endogenous sequencing." International Journal of Industrial Organization 17: 289296.

[16] Novshek, W. (1985): "Perfectly competitive markets as the limits of Cournot markets." Journal of Economic Theory 35: 72-82.

[17] Ono, Y. (1982): "Price leadership: A theoretical analysis." Economica 49: $11-20$.

[18] Rassenti, S.J., and Wilson, B.J. (2004): "How applicable is the dominant firm model of price leadership." Experimental Economics 7: 271-288.

[19] Robson, A.J., (1990): "Duopoly with endogenous strategic timing: Stackelberg regained." International Economic Review 31: 263-274.

[20] Ruffin, R.J. (1971): "Cournot oligopoly and competitive behaviour." Review of Economic Studies 38: 493-502.

[21] Sadanand, A., and Sadanand, V. (1996): "Firm scale and the endogenous timing of entry: A choice between commitment and flexibility." Journal of Economic Theory 70: 516-530.

[22] Scherer, F.M., and Ross, D., (1990): "Industrial market structure and economic performance", 3rd edition. (Houghton Mifflin, Boston) 
[23] Sherali, H.D. (1984): "A multiple leader Stackelberg model and analysis." Operations Research 32: 390-404.

[24] Sherali, H.D., Soyster, A.L., and Murphy, F.H. (1983): "StackelbergNash-Cournot equilibria: Characterizations and computations." Operations Research 31: 253-276.

[25] Szidarovszky, F., and Yakowitz, S. (1977): "A new proof of the existence and uniqueness of the Cournot equilibrium." International Economic Review 18: 787-789.

[26] Tasnádi, A. (2000): "A price-setting game with a nonatomic fringe." Economics Letters 69: 63-69.

[27] Tasnádi, A. (2004): "On Forchheimer's model of dominant firm price leadership." Economics Letters 84: 275-279.

[28] Tesoriere, A. (2008): "Endogenous timing with infinitely many firms." International Journal of Industrial Organization 26: 1381-1388.

[29] Tirole, J. (1988): "The theory of industrial organization." (MIT Press, Cambridge MA)

[30] Tobin, R.L. (1992): "Uniqueness results and algorithm for StackelbergCournot-Nash equilibria." Annals of Operations Research 34: 21-36.

[31] Žigić, K. (2008): "Stackelberg leadership with product differentiation and endogenous entry: Some comparative static and limiting results." CERGE-EI working paper, No 369. 